\title{
AFG: TECHNICAL ASSISTANCE FOR PILOT ENVIRONMENT PROJECTS
}

\section{Introduction}

1. On $12^{\text {th }}$ July 2007, The Financial Times (FT) published an article accusing the Asian Development Bank (ADB) of wasting money, time and credibility. The article suggests that several ADB technical assistance (TA) projects in Afghanistan did not deliver results and were poorly managed, and that reports by a consultant on project irregularities had not been taken seriously by ADB. This Information Paper provides information on the TAs, their performance, ADB's response to the complaints, and further steps to be taken.

\section{Background}

2. ADB approved four TA grants in 2002 and 2004 to promote sound environment and natural resource management in Afghanistan. Three of them received financing from the UK Government (via DFID), the Danish Government, and the Global Environment Fund (GEF). The TAs are as follows:

- TA-AFG 3874: Capacity Building for Reconstruction and Development, approved on 30 May 2002. The TA amount of $\$ 14.5$ million was financed by TASF. A small component of $\$ 300,000$ was for establishing the environmental agency capacity.

TA-AFG 4415: Kabul Air Quality Management, approved on 15 October 2004, with the Danish Government financing of $\$ 450,000$.

TA-AFG 4461: Poverty Reduction and Rural Renewable Energy Development, approved on 13 December 2004, with the UK Government financing of $\$ 750,000$.

TA-AFG-4541: Natural Resources Management and Poverty Reduction, approved on 23 December 2004, with the UK Government financing of $\$ 810,000$ and the GEF financing of $\$ 975,000$.

3. The ADB's country strategy for Afghanistan focuses on building and rehabilitating roads, power transmission lines, irrigation infrastructure, and on governance and capacity building. The environment and natural resources TAs included components for pilot or demonstration projects for innovative environmentally sound technologies. The pilots involved relatively small capital outlays and called for the demonstration of technologies related to:

\section{Micro hydro \\ Drip irrigation \\ Solar energy}

4. TA implementation work was directed from Kabul, by an ADB staff member on secondment at the time to the Afghan government. The staff has since resigned from the ADB.

\section{TA Progress and Outcomes}

5. The TAs are broad and several TA components, such as the micro-hydro projects, performed well, but others performed poorly. The experience with drip irrigation and selected solar panel pilots was disappointing. On the whole and with the benefit of hindsight, the TAs were too ambitious and inappropriate for the conditions prevailing in Afghanistan. The 
institutional, technical and financial capacity to operate and maintain such technologies was largely absent in the country. As a result, there were long delays in implementation, and, in some cases, failure to achieve the intended outcomes.

6. In at least two of the pilot cases, key conditions for project success and possible replication were missing.

\section{Tree Planting and Drip Irrigation}

While the concept of drip irrigation to support a tree planting program was fundamentally a sound one, the conditions around Kabul made it difficult to ensure that the trees were protected and the irrigation system maintained. About half of the trees planted survived, but the other half did not. The site was not properly secured during this planting phase, and many seedlings were damaged by animals and children. Although there was Government ownership and support for the project, implementation capacity was weak.

\section{Renewable energy; use of solar panels}

Afghanistan has a huge electricity shortage. Renewable energy is an option being explored by the Government and the private sector. Solar energy is one of the promising options, but unlike wind and small hydro power, this technology is not particularly well known in the country. The pilot project was supposed to show how this technology could work. It was meant to encourage public interest and to stimulate uptake from the communities. While the idea was generally sound, the mistake made was the choice of site for the demonstration and outreach work. Although there was merit in placing the panels in a place where a large number of people would see them in operation, the decision to locate the pilot project at a site that some people might find insensitive - at the tomb of a former tribal leader and fighter - was not.

\section{TA Consultants}

7. The TAs required the services of consultants. Several were employed and managed by the staff member mentioned above. One of the consultants felt that he had been rated unfairly by the ADB staff member. The consultant then made allegations regarding irregularities under the TAs (and also complained about his marginal performance rating). It should be noted that similar reports were received from other consultants working on the TA assignments, although no formal complaints were lodged by them. Later, the consultant reported the same allegations to the UK and Danish governments.

8. ADB reacted to these allegations through the following actions:

Central Operations Services Office (COSO) reviewed the consultant's allegations, referred them to Office of the Auditor General (Integrity Division) [OAGI] and suspended the performance evaluation process, and advised the consultant of these actions.

- COSO and OAGI reviewed and ultimately changed the performance rating to satisfactory, and advised the consultant this performance evaluation would not prejudice his opportunities for further consulting engagements with ADB.

- OAGI screened the allegations.

- The Afghanistan Resident Mission (AFRM) commissioned two consultants to carry out an operational review of the TAs. 
9. The OAGI concluded that there was no prima facie evidence of fraud and corruption as defined under ADB's Anticorruption Policy. OAGI advised that the handling of staff misconduct or mismanagement of the TA was outside of its mandate and jurisdiction, and referred the matter to BPHR and CWRD for appropriate handling. This information was communicated to the donors and the consultant. The operational review by AFRM concluded that the TAs worked well on the whole, but that some of the pilot subcomponents did not. The TAs have since been restructured. The core activities under the TAs are ongoing and will continue until October 2007.

\section{Independent Audit}

10. Notwithstanding the operational audit conducted by the Afghanistan Resident Mission on the TAs, in view of the nature of the complaints, ADB decided to commission a full and independent audit on each of the TAs. It was initially determined that CWRD would engage outside independent auditors to carry out the audit and that the auditors would report to CWRD. The terms of reference for this work have been drafted by CWRD and OAGF in consultation with DFID. The Danish authorities have also been given a copy of the proposal. The objective is to conduct a full performance and fiduciary audit of the TAs (all the components, not just the subcomponents criticized in the FT article). The audit will also investigate any breach of ADB's Anticorruption Policy.

11. In view of recent events, ADB management has taken further steps to ensure the integrity of the independent audit process. The outside independent auditors will be engaged, supervised and will report to OAGI. No ADB staff members previously involved in the carrying out (however tangentially) of the TAs, or supervising the TAs will be involved in any way in the supervision of the implementation of the audit. OAGI shall be responsible for ensuring that the audit is carried out thoroughly and quickly. The audit findings will be shared with the donors and the larger community. Any necessary follow up actions from ADB will await the findings of the independent audit. 